\title{
Proton pump inhibitors can reverse the YAP mediated paclitaxel resistance in epithelial ovarian cancer
}

\author{
Jing He $\mathrm{He}^{1,2,3+}$, Xiao-Yan Shi ${ }^{4 \dagger}$, Zhi-min Li ${ }^{5}$, Xiao-hua Pan ${ }^{1,2}$, Ze-Lian Li ${ }^{1,2}$, Ying Chen ${ }^{1,2}$, Shi-Jie Yan ${ }^{1,2^{*}}$ and \\ Lan Xiao ${ }^{1,2^{*}}$ (D)
}

\begin{abstract}
Background: Several reports indicated that the expression of Yes-associated protein (YAP) was associated with multi-drug resistance. Acidic microenvironment increased by the overexpression of vacuolar-ATPase (V-ATPase) was also observed in tumor growth and drug resistance. We hypothesize that proton pump inhibitors (PPIs), currently used in the anti-acid treatment of peptic disease, could inhibit the acidification of the tumor microenvironment and increase the sensitivity of tumor cells to cytotoxic agents. Thus, our objective is to explore the reversal of drug resistance by the inhibition of YAP through specific PPIs in the epithelial ovarian carcinoma (EOC) cells. .

Results: We found that V-ATPase D1 was a positive regulator of YAP. Sub-lethal doses of the proton pump inhibitor esomeprazole (EMSO) in combination with paclitaxel (PTX) increased the PTX sensitivity in PTX-resistant EOC cells, as compared to PTX single treatments by inhibiting YAP and reserving pH gradient created by the V-ATPase D1. Moreover, sub-lethal doses of EMSO combined with PTX decreased autophagy and improved caspases independent apoptosis of PTX-resistant EOC cells.

Conclusions: These results suggested that sub-lethal doses of esomeprazole reverse YAP-mediated PTX resistance through the inhibiting of both YAP expression and acidic tumor microenvironment created by the V-ATPase D1. Therefore, we think the use of PPIs represents a promising strategy to improve the effectiveness of anti-EOC.
\end{abstract}

Keywords: Vacuolar H + -ATPase, YAP, Proton pump inhibitors (PPI), Paclitaxel resistance, Epithelial ovarian carcinoma (EOC)

\section{Background}

In tumor cells, YAP (Yes-associated protein) is closely associated with tumorigenesis as one of the major transcription activation factors, plays an important role in regulating cell proliferation and organ development [1]. YAP is overexpressed, and is connected with multi-drug resistance [2, 3]. Our previous study [4] demonstrated that YAP was highly expressed in cisplatin-resistant EOC cancer cells. As a new anti-tubulin drug [5], paclitaxel (PTX) can raise the binding ability of 14-3-3 protein with YAP while remaining the stability of tublins and maintaining YAP in a phosphorylation status [6].

\footnotetext{
* Correspondence: ysj5851@126.com; emma_02000@163.com ${ }^{+}$Jing $\mathrm{He}$ and Xiao-Yan Shi contributed equally to this work.

'Department of Obstetrics \& Gynecology, First Affiliated Hospital, An Hui Medical University, Hefei 230020, Anhui, People's Republic of China Full list of author information is available at the end of the article
}

However, the inhibition of PTX by YAP can be reversed by the up-regulation of YAP [7].

Cancer cells survival and proliferation in competition with somatic cells and according to the physical and biological properties of their microenvironment. The constant high level of glycolytic activity in tumor cells leads to an increased production of lactic acid and a decreased $\mathrm{pH}$ of the extracellular microenvironment. Thus, in tumor cells, V-ATPases maintains an appropriate relatively neutral intracellular $\mathrm{pH}$ and an acidic extracellular $\mathrm{pH}$ [8]. The acidic microenvironment increased by overexpression of V-ATPases is observed in tumor growth, metastasis and chemoresistance [9]. In addition, several studies have demonstrated that PPIs (proton pump inhibitors), which directly inhibit V-ATPase at the cellular level, has reverted chemoresistance of drug-resistant tumors [10-12]. YAP/

(c) The Author(s). 2019 Open Access This article is distributed under the terms of the Creative Commons Attribution 4.0 International License (http://creativecommons.org/licenses/by/4.0/), which permits unrestricted use, distribution, and reproduction in any medium, provided you give appropriate credit to the original author(s) and the source, provide a link to the Creative Commons license, and indicate if changes were made. The Creative Commons Public Domain Dedication waiver (http://creativecommons.org/publicdomain/zero/1.0/) applies to the data made available in this article, unless otherwise stated. 
TAZ activation and a shift toward a glycolytic metabolism are commonly observed during tumor progression [13]. YAP is regulated by diverse mechanisms including microenvironmental factors [14]. V-ATPase D1 also known as ATP6V0D1, is the D subunit of the V0 domain. Expressed ubiquitously, V-ATPase D1 acts in concert with other V0 subunits to catalytically acidify a variety of intracellular compartments. V-ATPase D2 has been implicated as a regulator of urine acidification, osteoclast fusion and bone formation. Furthermore, V-ATPase D2 has been identified as a dendritic cell marker. Therefore, we wondered whether the inhibition of V-ATPase D1 through PPI can reserve the PTX resistance caused by the over-expression of YAP, and this may lead to the clinical use of PTX.

In the current study, we find a novel role of V-ATPase D1 in correlation with YAP. PTX resistance of the EOC cancer cells can be reversed by EMSO co-treatment and the YAP inhibition. Furthermore, we uncovered a downloaded of a novel V-ATPase D1/YAP signaling pathway, which may be targeted in EOC treatment. Thus, we have a clinical proof of concept that PPI may well be included in new anti-cancer strategies.

\section{Results \\ YAP is highly expressed in EOC and is directly regulated by V-ATPase D1 expression}

We found that both V-ATPase D1 and YAP were overexpressed in EOC tissues. V-ATPase D1 was predominantly observed in the cytoplasm of the cells (Fig. 1a). VATPase D1 expression was observed only in two normal ovarian epithelium but was expressed in 33 of 50 EOC tissues $(66 \%)$. Immunohistochemical analysis of YAP positive expression was detected in both nuclear and cytoplasm cell compartments. The positive expression rates of YAP in EOC tissues were 56\% (28/50) (Fig. 1b). High nuclear YAP levels were observed in ovarian tumor samples than nuclear V-ATPase D1 levels. The normal ovarian epithelium just showed weak staining for YAP in the cytoplasm. The expression of V-ATPase D1 correlated with YAP expression in the EOC tissues $(r=0.467, P<0.01)$. The expression levels of V-ATPase D1 and YAP mRNA were higher in EOC tissues, compared with normal ovarian epithelium tissues $(p<0.05$, Fig. 1c). Since V-ATPase D1 expression was increased in PTX-resistant EOC cells, we next examined the effect of V-ATPase D1 silencing on YAP levels in PTXresistant A2780/T cells. We used a short hairpin RNA against V-ATPase D1(shRNA) or a non targeting scrambled short hairpin RNA (sh-scr). Representative data from A2780/T cells is shown in Fig. 1d. The V-ATPase D1 shRNA transfected cells exhibited 3.34-fold and 3.16-fold inhibition at V-ATPase D1 and YAP mRNA levels, compared with scrambled control, respectively (Fig. 1d). The VATPase D1 silencing was further confirmed at protein level, a 3.60-fold and 2.25-fold reduction in V-ATPase D1 and
YAP, a 1.95-fold promotion of p-YAP protein expression were observed by western blotting, respectively (Fig. 1e). As shown in Fig. 1f, downregulation of V-ATPase D1 impaired the transcriptional activity of YAP in the luciferase assay in A2780/T cells. Knocking down the expression of V-ATPase D1 in A2780/T cells impaired the expression of target proteins downstream of YAP (Fig. 1g). These results suggested that V-ATPase D1 activated the transcriptional activity of YAP in PTX-resistant A2780/T cells.

In addition, a comparison conducted between stages of ovarian cancer showed that the levels of expression of YAP and V-ATPase D1 were significantly higher in stage III-IV, compared to stage I-II. The high levels of YAP and V-ATPase D1 proteins were positively associated with lymphatic invasion, tumor grade, and tumor size in EOC patients (Tables 1 and 2).

\section{YAP-TEAD1 confers PTX-resistance to EOC cells}

The stability of PTX-resistant in A2780/T cells were compared to PTX-sensitive A2780 cells was confirmed by doseresponse curves (Fig. 2a). CCK-8 assay showed that A2780/ $\mathrm{T}$ achieved a high degree of resistance to PTX. The 48-h IC50 with PTX of the A2780 and A2780/T cells was $0.5 \pm$ $0.12 \mu \mathrm{mol} / \mathrm{L}$ and $9.3 \pm 0.5 \mu \mathrm{mol} / \mathrm{L}$, respectively (Fig. $2 \mathrm{~b}$ ). As shown in Fig. 2c, the expression of the corresponding proteins, P-gp, Cyr61, YAP were overexpressed and lower pYAP expressions in the A2780/T cells, compared with the A2780 cells. To further confirm the relationship between YAP and PTX resistance, we firstly over-expressed in YAPlow/PTX-sensitive A2780 cells (Fig. 2d), using plasmids expressing His-tagged YAP. Over-expression of YAP in A2780 cells induced a promotion of Cyr61, p-gp, YAP, and a suppression of p-YAP protein expression. Obviously, over-expression of YAP and lower p-YAP expression in A2780 cells significantly reduced its drug-sensitivity to PTX (Fig. 2d). Secondly, we knocked down YAP gene in YAPhigh/PTX-resistant A2780/T cells by using siRNAs. YAP silencing in A2780/T cells significantly suppressed Cyr61, p-gp, YAP and upregulated p-YAP protein expression. Correspondingly, YAP silencing in A2780/T cells sensitized theirs response to PTX treatments (Fig. 2e). Taken together, these results strongly confirmed that YAP is a biomarker for the resistant of EOC cells to PTX.

TEAD family members are YAP downstream coactivators. Multiple genes strongly correlated with tumorigenesis were regulated by TEAD family, including CTGF and Cyr61. Our results showed that Cyr61 and CTGF were highly induced by YAP expression in A2780/T cells, compared to A2780 cells (Fig. 1g). In ovarian cancer initiated cells, TEAD1 and TEAD4 were found to be expressed at significantly higher levels than in differentiated ovarian cancer cells. In this study, we focused on YAP downstream co-activators TEAD1. As shown in Fig. 2f, the expression of TEAD1 was 




A

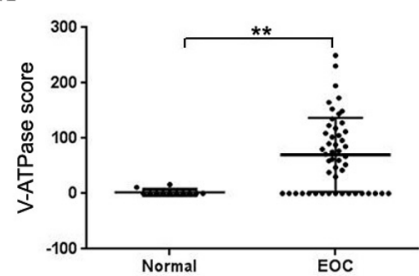

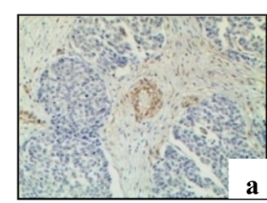
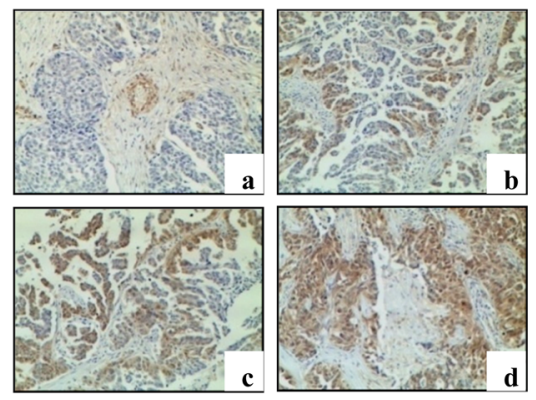

B

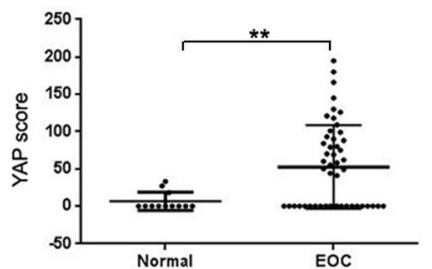

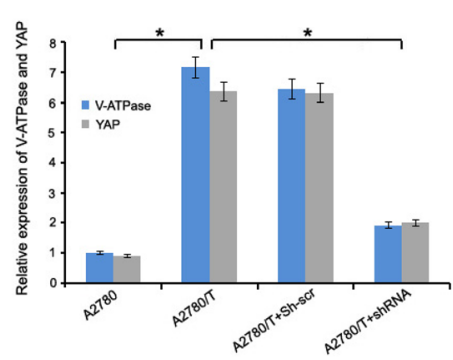

$\mathbf{F}$

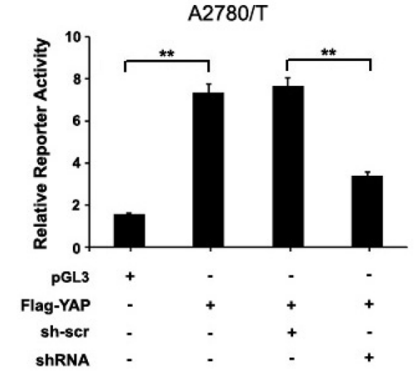

G

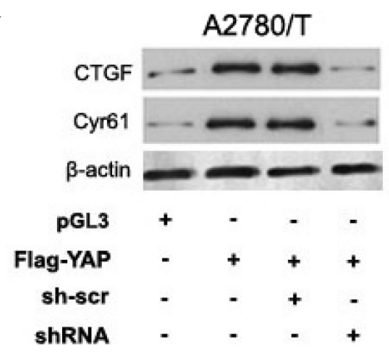

Fig. 1 YAP is highly expressed in EOC and is directly regulated by V-ATPase D1 expression. Immunohistochemical observation of V-ATPase D1 and YAP protein expression in normal ovarian epithelium and EOC tissues, a V-ATPase D1 and b YAP (with extremely weak staining (0), a weak staining $(+1)$, a moderate staining $(+2)$, a strong staining $(+3)$. All photographs were taken at original $200 \times$ magnification. The scores of $(\mathbf{a}) \mathrm{V}$ ATPase D1 and (b) YAP by beeswarm plot was shown in the bottom (**P $<0.01)$. c The mRNA level of V-ATPase D1 and YAP in normal ovarian epithelium and EOC tissues were determined using a real-time PCR kit. Data represent the mean and standard deviation (mean \pm SD) are from three independent experiments ( $\left.{ }^{*} P<0.05\right)$. $\mathbf{d}$ V-ATPase D1 and YAP expression assessed by Q-PCR analysis in EOC cell lines. Data (mean \pm SD) are from three independent experiments $(* P<0.05)$. e V-ATPase D1, YAP and P-YAP protein levels in A2780/T cells were performed by western blot. $\mathbf{f}$ Knocking down the expression of V-ATPase D1 in A2780/T cells impaired the transcriptional activity of YAP in the luciferase assay. $\mathbf{g}$ Knocking down the expression of V-ATPase D1 in A2780/T cells impaired the binding of YAP to the promoter region of CTGF and Cyr61

overexpressed in the A2780/T cells, compared with the A2780 cells. Next, we cloned the CTGF promoter into a basic luciferase reporter and found that it was potently activated by YAP but not by YAP-S94A, and the activation was further enhanced by TEAD1 co-expression (Fig. $2 \mathrm{~g}$ ). Expression of the dominant-negative TEAD1-C, but not the TEAD1-C-AD (in which the C-terminal YAPbinding domain was replaced by the YAP transactivation domain), blocked the activation of CTGF reporter by YAP (Fig. 2h). These results indicate that YAP activates the CTGF promoter through TEAD1.

\section{Effects of acidic pHe on V-ATPase D1 change}

PTX combination with sub-lethal doses of EMSO (130 and $150 \mu \mathrm{M})$ for $48 \mathrm{~h}$ induced a significantly expression decrease in V-ATPase D1 protein levels in A2780/T cells and A2780 cells (Fig. 3a). Confocal microscopy analysis confirmed the co-localization of V-ATPase D1 with the plasma membrane marker, pan-cadherin, suggesting that the isoform is expressed on the plasma membrane of both PTX-sensitive and PTX-resistant tumor cells, with elevated expression in PTX-resistant cells. Sub-lethal dose of EMSO for $48 \mathrm{~h}$ did induce a reduction of $\mathrm{V}$ ATPase D1 protein expression in both cell membrane and cytosolic compartments of A2780/T cells, as compare to control cells. V-ATPase D1 levels were slightly reduced in A2780 cells with sub-lethal dose of EMSO (Fig. 3b). The change in $\mathrm{pH}$ in two EOC cells was confirmed by EMSO treatment. Alterations in intracellular $\mathrm{pH}$ in two EOC cells were verified using the BCECF-AM $\mathrm{pH}$ indicator. Fluorescence was significantly decreased in PTX-resistant A2780/T cells, indicating that intracellular 
Table 1 Association of V-ATPase D1 expression with clinicopathological factors in epithelial ovarian carcinoma patients

\begin{tabular}{|c|c|c|c|c|c|c|}
\hline \multirow[t]{2}{*}{ Features } & & \multirow[t]{2}{*}{$n$} & \multicolumn{2}{|c|}{ V-ATPase D1 } & \multirow[t]{2}{*}{$x^{2}$} & \multirow[t]{2}{*}{$P$} \\
\hline & & & Positive & Negative & & \\
\hline \multirow[t]{2}{*}{ Mean age } & $>55$ & 31 & 21 & 10 & 0.110 & 0.740 \\
\hline & $\leq 55$ & 19 & 12 & 7 & & \\
\hline \multirow{2}{*}{$\begin{array}{l}\text { FIGO } \\
\text { stage }\end{array}$} & $|-| \mid$ & 12 & 3 & 9 & 11.828 & 0.001 \\
\hline & III-IV & 38 & 30 & 8 & & \\
\hline \multirow[t]{2}{*}{ Lymphatic invasion } & Positive & 34 & 28 & 6 & 12.662 & 0.000 \\
\hline & Negative & 16 & 5 & 11 & & \\
\hline \multirow[t]{3}{*}{ Pathological type } & Mucinous & 14 & 8 & 6 & 2.247 & 0.325 \\
\hline & Serous & 25 & 19 & 6 & & \\
\hline & Others & 11 & 6 & 5 & & \\
\hline \multirow[t]{3}{*}{ Tumor grade } & G1 & 10 & 2 & 8 & 14.925 & 0.001 \\
\hline & G2 & 24 & 16 & 8 & & \\
\hline & G3 & 16 & 15 & 1 & & \\
\hline \multirow{2}{*}{$\begin{array}{l}\text { Tumor } \\
\text { size }\end{array}$} & $<10$ & 34 & 18 & 16 & 8.074 & 0.004 \\
\hline & $\geq 10$ & 16 & 15 & 1 & & \\
\hline
\end{tabular}

$\mathrm{pH}$ was acidified by V-ATPase D1 inhibition. In contrast, intracellular $\mathrm{pH}$ showed no significant change in PTX-sensitive A2780 cells (Fig. 3c). Quantitative analysis showed that the intracellular $\mathrm{pH}$ decreased in A2780/T cells, but statistical significance was not achieved in A2780 cells (Fig. 3d). In summary, in both A2780/T and A2780 cells, V-ATPase D1 was co-localized in the cell plasma and membranes. Notably, we found higher

Table 2 Association of YAP expression with clinicopathological factors in epithelial ovarian carcinoma patients

\begin{tabular}{|c|c|c|c|c|c|c|}
\hline \multirow[t]{2}{*}{ Features } & & \multirow[t]{2}{*}{$n$} & \multicolumn{2}{|l|}{ YAP } & \multirow[t]{2}{*}{$x^{2}$} & \multirow[t]{2}{*}{$P$} \\
\hline & & & Positive & Negative & & \\
\hline \multirow[t]{2}{*}{ Mean age } & $>55$ & 31 & 17 & 14 & \multirow[t]{2}{*}{0.045} & \multirow[t]{2}{*}{0.833} \\
\hline & $\leq 55$ & 19 & 11 & 8 & & \\
\hline \multirow{2}{*}{$\begin{array}{l}\text { FIGO } \\
\text { stage }\end{array}$} & $|-| \mid$ & 12 & 1 & 11 & \multirow[t]{2}{*}{14.560} & \multirow[t]{2}{*}{0.001} \\
\hline & III-IV & 38 & 27 & 11 & & \\
\hline \multirow[t]{2}{*}{ Lymphatic invasion } & Positive & 34 & 26 & 16 & \multirow[t]{2}{*}{11.325} & \multirow[t]{2}{*}{0.001} \\
\hline & Negative & 16 & 2 & 14 & & \\
\hline \multirow[t]{3}{*}{ Pathological type } & Mucinous & 16 & 9 & 7 & \multirow[t]{3}{*}{3.852} & \multirow[t]{3}{*}{0.146} \\
\hline & Serous & 24 & 16 & 8 & & \\
\hline & Others & 10 & 3 & 7 & & \\
\hline \multirow[t]{3}{*}{ Tumor grade } & G1 & 10 & 2 & 8 & \multirow[t]{3}{*}{12.054} & \multirow[t]{3}{*}{0.002} \\
\hline & G2 & 24 & 12 & 12 & & \\
\hline & G3 & 16 & 14 & 2 & & \\
\hline \multirow{2}{*}{$\begin{array}{l}\text { Tumor } \\
\text { size }\end{array}$} & $<10$ & 36 & 15 & 21 & \multirow[t]{2}{*}{10.720} & \multirow[t]{2}{*}{0.001} \\
\hline & $\geq 10$ & 14 & 13 & 1 & & \\
\hline
\end{tabular}

plasma and membrane V-ATPase D1 expression in PTX-resistant A2780/T cells than PTX-sensitive A2780 cells. The A2780/T cells showed higher acidification activity as well.

\section{PPI reduced PTX resistance in EOC cells through the inhibition of YAP. Synergetic effects of the combination of PPI and PTX resulted in the inhibition of YAP and cytotoxicity to PTX-resistant EOC cells}

The cytotoxic effect of EMSO was investigated by employing a CCK-8 assay on A2780/T and A2780 cells. We found that EMSO treatment of A2780/T and A2780 cells resulted in anti-growth effects at sub-lethal doses in both cell types. The sub-lethal doses of EMSO were approximately 150 and $130 \mu \mathrm{M}$ in the A2780/T and A2780 cells, respectively (Fig. 4a). The decrease in the percentage of viability was statistically significant at low doses of PTX when combined with sub-lethal doses of EMSO $(P<0.01)$. Even at the lowest dose of PTX, 0.01 and $0.04 \mu \mathrm{M}$, the combination with sub-lethal doses of EMSO (150 and $130 \mu \mathrm{M})$ decreased viability dramatically, whereas PTX alone or in combinations with $50 \mu \mathrm{M}$ EMSO were ineffective in two cell types (Fig. 4b). The growth inhibitory effects of $130 \mu \mathrm{M}$ EMSO+PTX were significant at $0.01,0.05,0.25$ and $1.25 \mu \mathrm{M}$ in A2780 cells. On the other hand, the growth inhibitory effects of $150 \mu \mathrm{M}$ EMSO+PTX were significant at 0.04, 0.20, $0.90,5.0$ and $23 \mu \mathrm{M}$ in A2780/T cells. However, PTX combinations with $100 \mu \mathrm{M}$ EMSO did not result in a higher efficacy (Fig. 4b). We further examined if there were any synergistic, additive, or antagonistic interactions between EMSO and PTX. As expected, the resulting interaction of sub-lethal doses of EMSO combinated with PTX was synergism at all doses except for the $130 \mu \mathrm{M}$ EMSO+7.50 $\mu \mathrm{M}$ PTX combination in A2780 cells, which was an additive interaction (Table 3).

We also demonstrated the specific and significant inhibition of PTX-resistance related mRNA and protein expression in A2780 and A2780/T exposed to PTX (0.25 and $2 \mu \mathrm{M})$, EMSO (130 and $150 \mu \mathrm{M}$ ) alone or to the combination with PTX. MDR1 expression was very high in the A2780/T cells, but nearly absent in the parental A2780 cells. The levels YAP and cyr61 expression in the A2780/T cells co-treated with EMSO+PTX were significantly decreased, compared to EMSO and PTX alone treatment. However, statistical significance was not achieved neither for YAP nor cyr61 expression in A2780 cells using the same treatment combination (Fig. 4c). As shown in Fig. 4de, compared to YAP expression, p-gp expression was very high in the A2780/T cells, but nearly absent in the parental A2780 cells. Q-PCR and confocal analysis revealed that YAP and its downstream target Cyr61 was inhibited by 


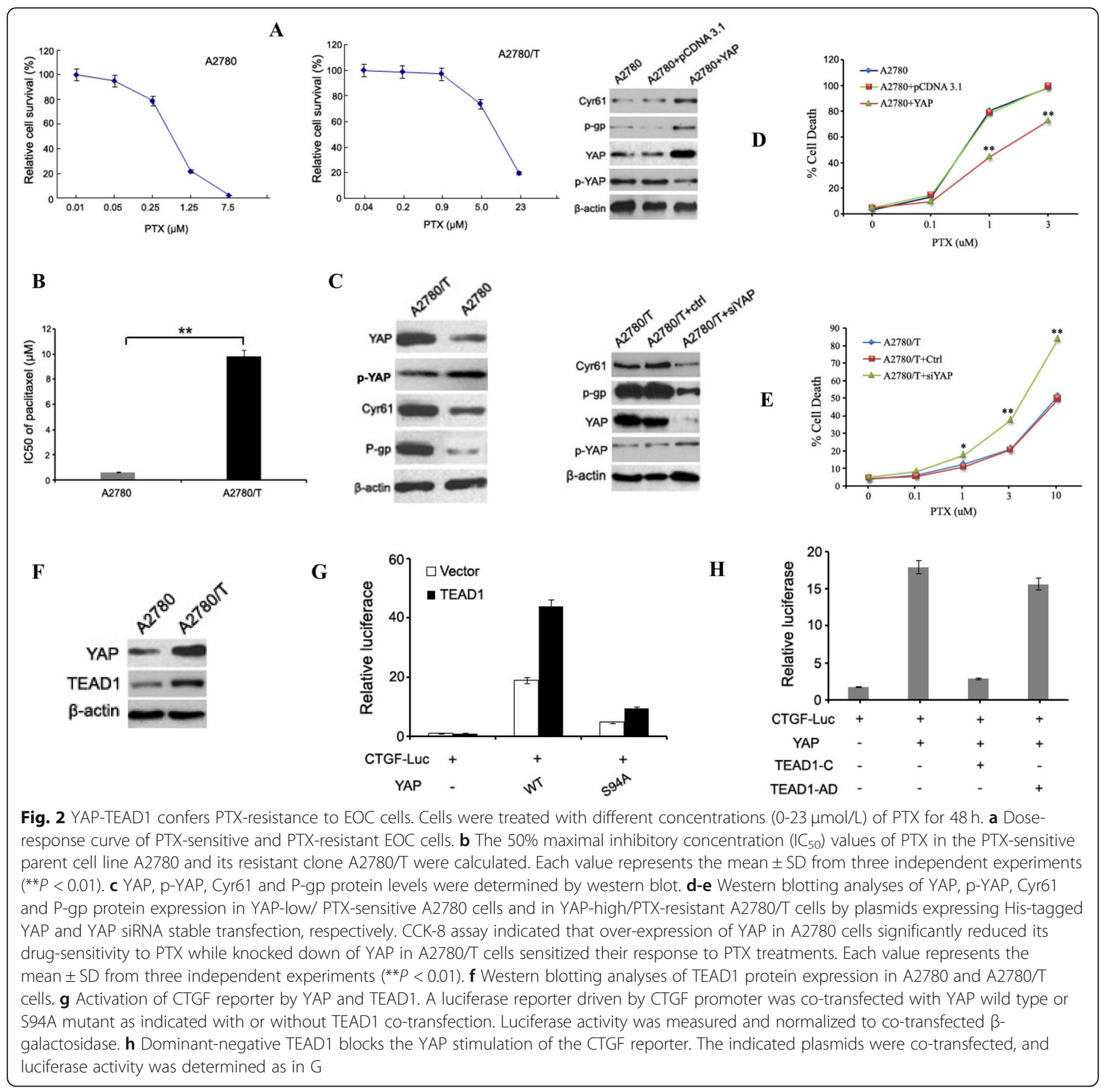

combination therapy with sub-lethal doses of EMSO and PTX in the A2780/T cells, compared to EMSO and PTX alone (Fig. 4d-e). Moreover, the increase of p-YAP expression and decrease of p-gp and TEAD1 expression in the two ovarian cancer cells were reversed by a co-treatment with EMSO+PTX (Fig. 4d).

It has been well documented that the PI3K/AKT pathway is essential for the proliferation and invasion of tumor cells, and activation of the PI3K/AKT signaling pathway is regulated by YAP. Western blots of two cell lysates showed that a combination treatment with PTX + EMSO did affect the phosphorylation status of Akt (Fig. 4f). Therefore, co-treatment with PTX + EMSO may decrease
YAP nuclear localization and activity and causes more sensitivity to PTX in the two ovarian cancer cells.

PPI-mediated apoptosis was revealed using a caspaseindependent apoptotic-like cytotoxicity upon PTX treatment of EOC cells

To assess cell apoptosis in A2780 and A2780/T cells, apoptosis rate was measured by flow cytometry and Hoechst-33342 with PTX $(0.25$ and $2 \mu \mathrm{M})$ alone and in combination with EMSO (130 and $150 \mu \mathrm{M})$. We found that the apoptosis rate in the two EOC cells induced by sub-lethal doses of EMSO was about 2-fold than that of untreated cells, suggesting that the specific cytotoxic 


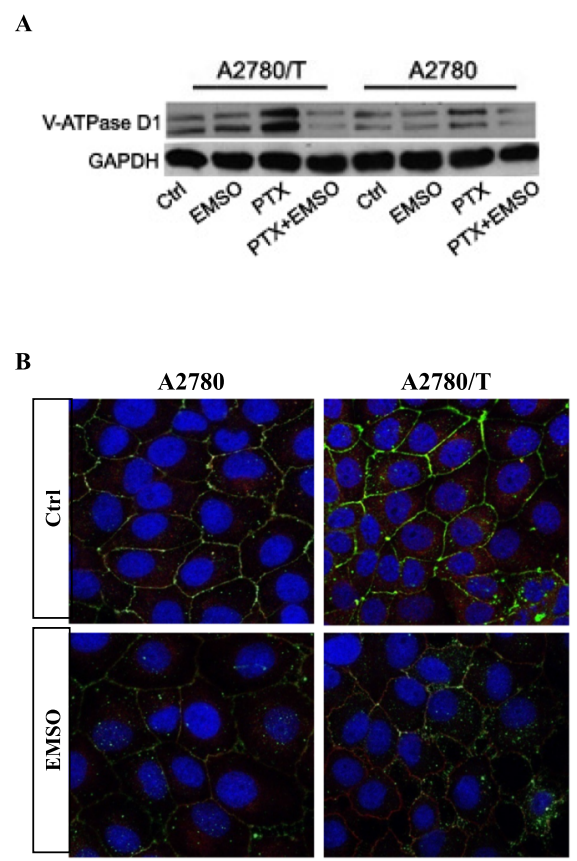

C
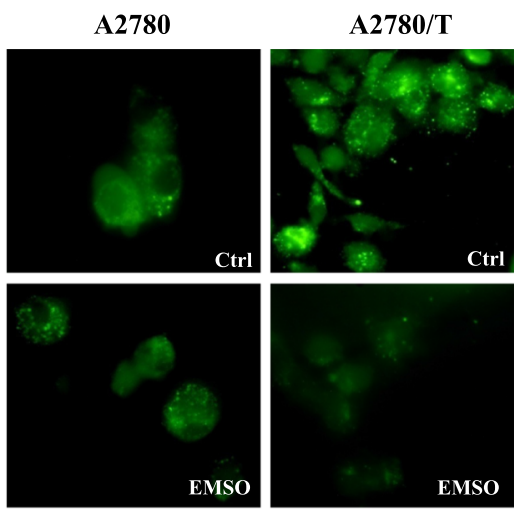

D

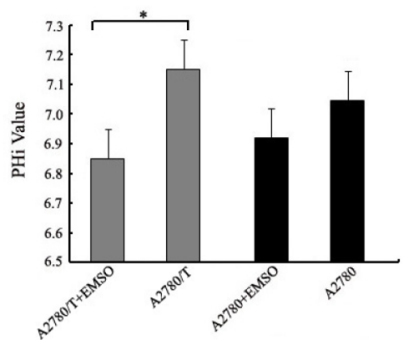

Fig. 3 Effects of acidic pHe on V-ATPase D1 change. a Total protein from PTX- resistant EOC cells and respective sensitive phenotypes were immuno-blotted with anti-V-ATPase D1. b Confocal microscopy showing V-ATPase D1 (green dots) and plasma membrane (red/orange staining) in A2780 and A2780/T cells. DAPI in blue color represents nuclear staining. Merged images (yellow regions). Original magnification $\times 600$. Representative images from three independent experiments are shown. c Cytosolic pH was estimated using pH sensitive dye BCECF-AM. Significantly decreased intracellular pH was observed in EMSO co-treated with PTX in A2780/T cells using BCECF-AM and fluorescence microscopy (488/535 nm, Magnification $\times 600)$. d The corresponding intracellular $\mathrm{pH}$ was obtained from the $\mathrm{pH}$ calibration curve. Values are means \pm S.E.M of two independent experiments performed in triplicate $\left({ }^{*} P<0.05\right)$

effects of EMSO in EOC cells were apoptosis-related. EMSO co-treatment show synergistic effect on PTXinduced apoptosis in two ovarian cancer cells. Interestingly, the increase rate in apoptosis with EMSO was higher in PTX-resistant A2780/T cells than in PTXsensitive A2780 cells (Fig. 5a-b). Afterwards, A2780/T cells restored PTX sensitivity.

We next examined the possible mechanisms responsible for the apoptotic effects of sub-lethal doses of EMSO combined with PTX, we evaluated its effects based on the activation of caspases. Morphological analysis showed that sub-lethal doses of EMSO combined with PTX had no significant effect on caspase- 3 and caspase8 activities in the two EOC cell lines (Fig. 5c). To confirm the role of caspases in sub-lethal doses of EMSO combination with PTX-induced cell death, the pan-caspases inhibitor z-VAD-fmk was used at $20 \mu \mathrm{M}$ (Fig. 5d). We observed that preincubation with z-VAD-fmk, had no significant effect on co-treatment PTX + EMSOinduced apoptosis in the two EOC cells. This suggests that activated caspases are not instrumental for the combination of EMSO with PTX-induced apoptosis in the EOC cells.

\section{Autophagy flux inhibited by the combinations of PTX with sub-lethal doses of EMSO}

In addition, we determined if the level of autophagy flux was inhibited by the combination of PTX and sub-lethal doses of EMSO with the autophagy marker p62 used as an indicator of autophagic flux whose levels would decrease when there was an active autophagic flux within the cell [15]. To investigate the role of PTX in inducing autophagy, we evaluated the levels of $\mathrm{p} 62$ protein in the A2780 and A2780/T cells exposed to PTX (0.25 and $2 \mu \mathrm{M})$, EMSO (130 and $150 \mu \mathrm{M})$ alone or in combination after $48 \mathrm{~h}$. Our results showed that PTX-resistant A2780/ $\mathrm{T}$ cells expressed significantly lower levels of p62 when compared with the PTX-sensitive A2780 cells. Importantly, the levels of autophagy-related proteins 5 (ATG5) were higher in A2780/T when compared with A2780 cells. Inversely, co-treatment with sub-lethal dose of EMSO for $48 \mathrm{~h}$ induced a modest increase in p62 protein expression in the A2780/T cells (Fig. 6a). We further demonstrated that suppression of PTX induced autophagy by sub-lethal doses of EMSO combined with PTX in the A2780/T cells, was associated with a noticeable decrease in the ATG5 (Fig. 6b). But the same effect was not confirmed in the 


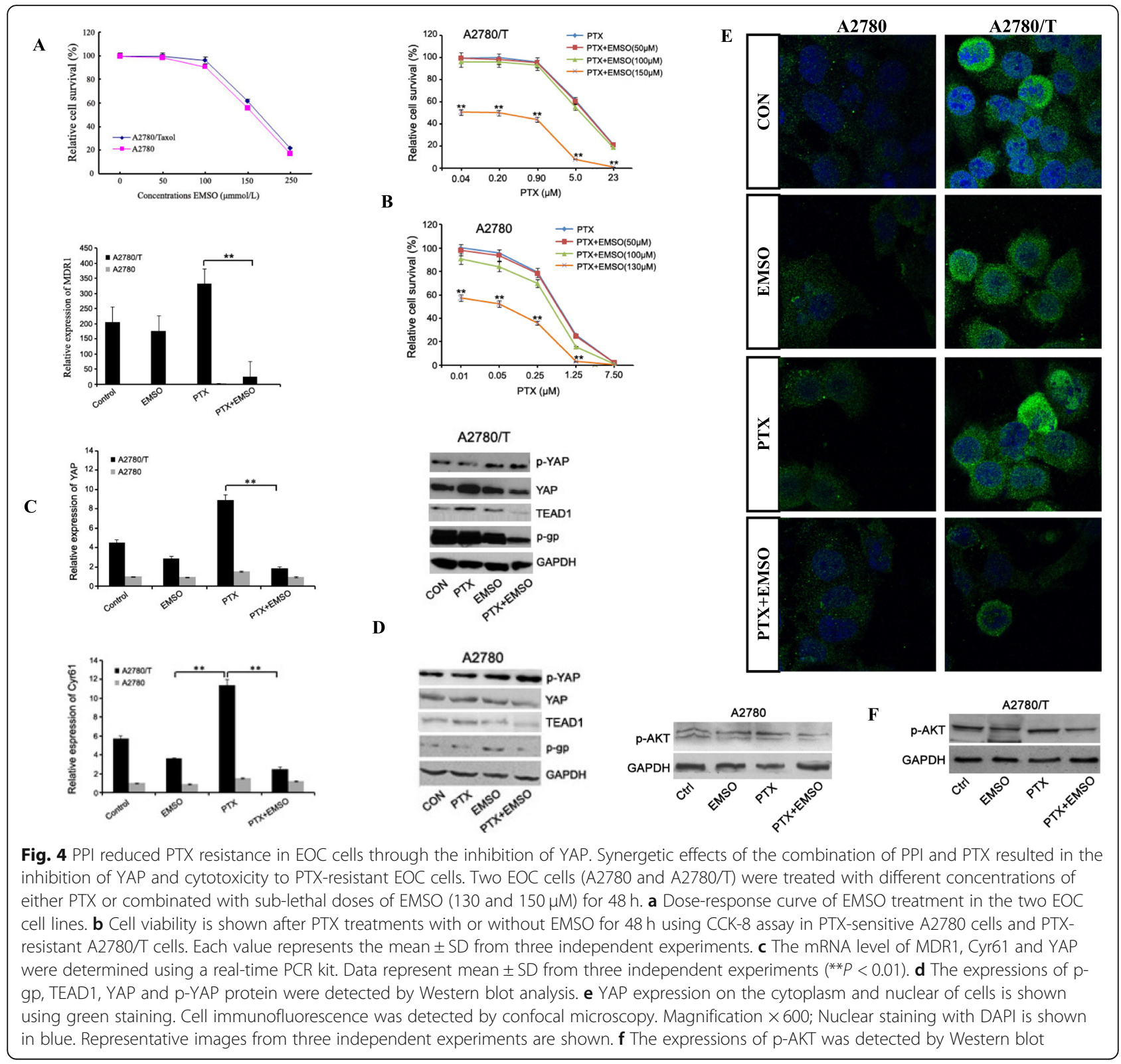

A2780 cells. Thus, co-treatment with sub-lethal doses of EMSO inhibited autophagy and enhanced PTX cytotoxicity. Actually, overexpression of ATG5 not only promotes autophagy but also promotes apoptosis [16]. Further work is required to understand how ATG5 in regulating proapoptotic signaling pathways.

We also found that PTX treatment preferentially induced GFP-LC3B puncta in the A2780/T cells but not in the A2780 cells. There was also an increased accumulation of LC3B in the presence of a sub-lethal dose of EMSO combined with PTX with a strongly enhanced the presence of punctuate fluorescence in A2780/T cells (Fig. $6 \mathrm{c}-\mathrm{d})$, indicating ESOM partially reduced autophagic flux.
These findings suggest that co-treatment with a sublethal dose of EMSO likely causes the accumulation of autophagosomes and slows down the autophagic flux.

\section{Discussion}

Acidic microenvironment increased by overexpression of $\mathrm{V}$-ATPases has been observed in malignant tissues. It was also found that higher expression of V-ATPase mRNA was associated with a significant poor survival [17]. Our results revealed that V-ATPase D1 silencing cells exhibited 2.25 -fold inhibition in YAP protein level. The inhibition of V-ATPase D1 reduces YAP activities in A2780/T cells. Knocking down the expression of $\mathrm{V}$ - 
Table 3 Paclitaxel and EMSO Combination Index (CI) against A2780 and A2780/T Cells

\begin{tabular}{|c|c|c|c|}
\hline Combination type & Inhibitory rate & $\mathrm{Cl}$ & Interaction type \\
\hline $\mathrm{A} 2780+\mathrm{PTX}(0.05)$ & 4.7 & & \\
\hline $\mathrm{A} 2780+\mathrm{EMSO}(50)$ & 1.6 & & \\
\hline $\mathrm{A} 2780+\mathrm{PTX}(0.05)+\mathrm{EMSO}(50)$ & 6.3 & 1.0 & Additive \\
\hline A2780+ PTX(0.25) & 29.1 & & \\
\hline $\mathrm{A} 2780+\mathrm{EMSO}(100)$ & 9.2 & & \\
\hline $\mathrm{A} 2780+\mathrm{PTX}(0.25)+\mathrm{EMSO}(100)$ & 38.3 & 1.0 & Additive \\
\hline A2780+ PTX(1.25) & 72.3 & & \\
\hline A2780+ EMSO(130) & 44.2 & & \\
\hline A2780+ PTX(1.25) + EMSO(130) & 95.3 & 0.94 & Synergistic \\
\hline A2780/T+ PTX(0.04) & 0.7 & & \\
\hline $\mathrm{A} 2780 / \mathrm{T}+\mathrm{EMSO}(50)$ & 1.2 & & \\
\hline $\mathrm{A} 2780 / \mathrm{T}+\mathrm{PTX}(0.04)+\mathrm{EMSO}(50)$ & 2.0 & 1.0 & Additive \\
\hline $\mathrm{A} 2780 / \mathrm{T}+\mathrm{PTX}(0.90)$ & 1.6 & & \\
\hline $\mathrm{A} 2780 / T+\mathrm{EMSO}(100)$ & 2.7 & & \\
\hline $\mathrm{A} 2780 / \mathrm{T}+\mathrm{PTX}(0.90)+\mathrm{EMSO}(100)$ & 4.3 & 1.0 & Additive \\
\hline $\mathrm{A} 2780 / \mathrm{T}+\mathrm{PTX}(5.0)$ & 24.3 & & \\
\hline $\mathrm{A} 2780 / \mathrm{T}+\mathrm{EMSO}(150)$ & 43.9 & & \\
\hline $\mathrm{A} 2780 / \mathrm{T}+\mathrm{PTX}(5.0)+\mathrm{EMSO}(150)$ & 85.4 & 0.91 & Synergistic \\
\hline
\end{tabular}

$\mathrm{Cl}<1$, synergistic; $\mathrm{Cl}=1$, additive; or antagonistic, $\mathrm{Cl}>1$

ATPase D1 in A2780/T cells prevented the expression of target proteins downstream of YAP. Overall, our studies have provided a novel mechanism in PTXresistance ovarian cancer cells through the activating of YAP transcriptional activity by V-ATPase D1.

Previous research has reported that over-expression of YAP promotes PTX-resistance in ovarian cancer cells [18]. The precise mechanisms by which YAP enhances drug resistance remain unclear. In the present study, we found that YAP was significantly elevated in A2780/T cells, compared with A2780 cells. To further confirm the relationship between YAP and PTX resistance, overexpression of YAP by stable transfection enhanced the expression level of YAP and contributed to PTX -resistance in the A2780 cells. Correspondingly, suppression of YAP by siRNA effectively inhibited YAP expression, resulting in PTX-sensitivity in A2780/T cells. Our immunostaining results also showed that TEAD1 was positively correlated with YAP expression, suggested that TEAD1was a direct binding partner of YAP. Therefore, we speculate that modulating YAP and TEAD1 activities may be an effective strategy to prevent the PTXresistance in ovarian cancers.

Treatment using PPIs has been proposed as a valid and feasible approach because of the relatively low toxicity and potential selectivity of these drugs. It has been reported that PPIs are chemosensitizing as well as cytotoxic drugs, active against several human tumor cells, such as osteosarcoma $[19,20]$, melanoma [21, 22], gastric carcinoma [23-25], pancreatic cancer [26] and breast cancer [27-29]. In this context, we hypothesized that the V-ATPase blocker PPI could reverse the YAPmediated PTX-resistance in EOC cells. Our results demonstrated that a sub-lethal dose of EMSO affected the membrane V-ATPase D1 expression, as well as regulated the transmembrane $\mathrm{pH}$ gradient in EOC cells, suggesting that V-ATPase D1 mediated the acidic tumor microenvironment formation. These data are in agreement with one study demonstrating in MCF-7 breast carcinoma cell line that a low extracellular $\mathrm{pH}$ induces higher resistance to PTX [30].

When used in combination, the PPIs improve the efficacy of the anti-cancer drugs. This study further supports these previous observations. In a lung cancer study, it has been proven that the combination of EMSO with chemotherapeutics results in a more pronounced cytotoxic effect [31]. In our study, apparent and statistically significant cytotoxic effects were observed in a combinated treatment with a sub-lethal dose of EMSO and PTX. We also found that PTX combined with sublethal doses of EMSO generated strong synergism effect. A sub-lethal dose of EMSO could effectively inhibit YAP protein and its down-stream proteins. Moreover, our results showed that the down-regulation of MDR1/P-gp protein expression. In addition, we observed that the decrease in phosphor-AKT levels was accompanied by lower cell survival rates and PTX-sensitivity in A2780 and A2780/T cells exposed to a PTX + EMSO co- treatment. Thus, our results indicated a substantial reversal in PTX-resistance cells, was YAP-mediated in EOC cells.

To improve treatment efficacy, it is crucial to investigate the precise molecular mechanism of PPIs in EOC, which may occur through: (i) inhibition of drug extrusion from cells via P-glycoprotein or other MDR-related mechanisms [18]; (ii) increase in anti-apoptotic molecules [32]; and (iii) acidic endosomes, which are an important step in the maturation of autophagosomes and PPIs which inhibit autophagy [33]. Some human cancers, including ovarian, gastrointestinal, prostate and breast cancers [34-37] exhibit high levels of autophagic activity. Studies have described the induction of autophagy in response to therapeutic agents [38]. For example, cisplatin and PTX were able to induce autophagy in A549 lung cancer cells [39]. Increasing evidence suggests that inhibition of autophagy augments cytotoxicity caused by anticancer drugs in preclinical models [40]. Inhibitors of autophagy that can be used in vivo include CQ (chloroquine), HCQ (hydroxychloroquine) and PPIs. Co-treatment with pantoprazole was able to inhibit autophagy and enhance cytotoxicity in vivo [41]. 


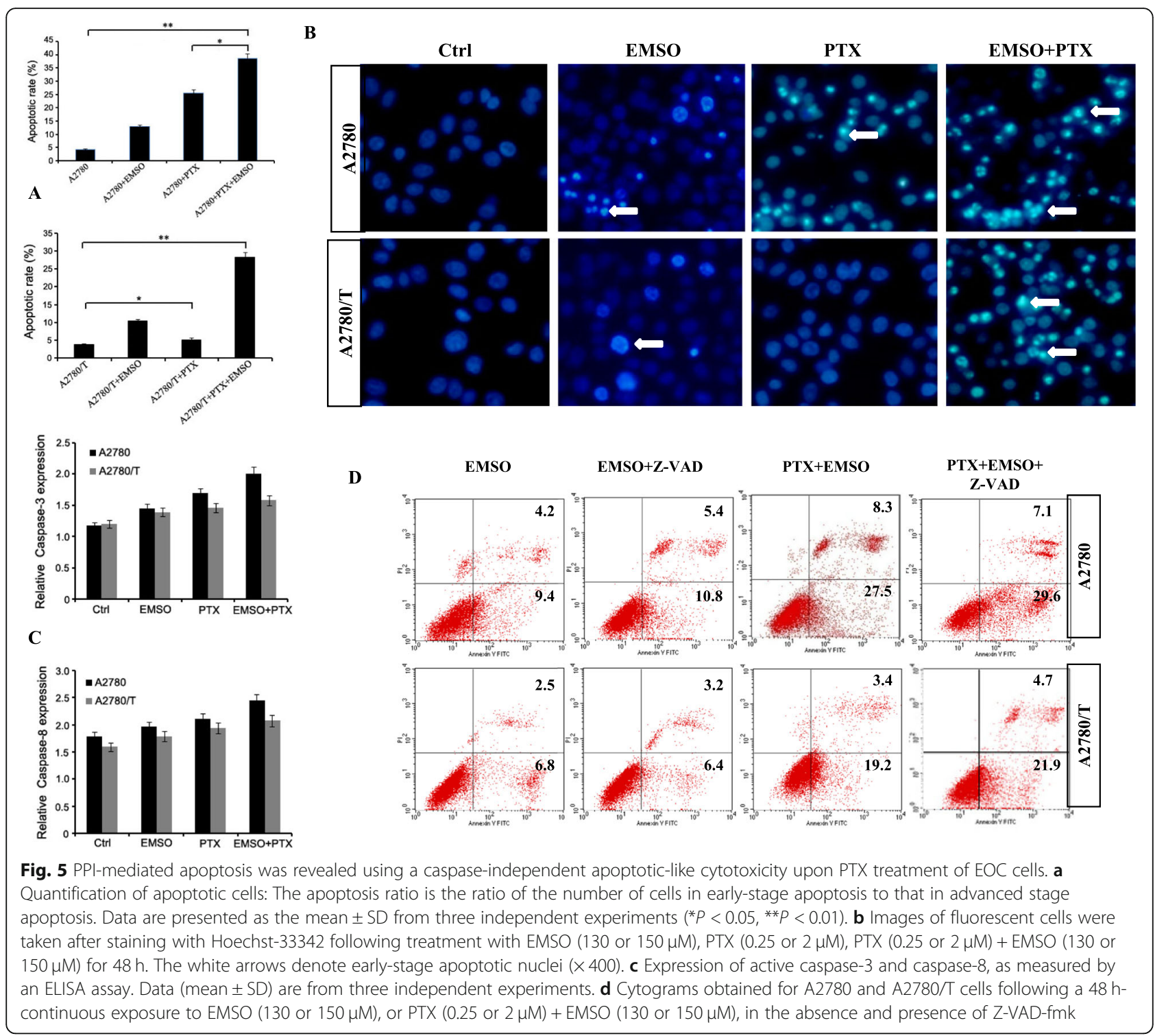

On the search for cellular mechanisms that mediate the effect of EMSO in EOC cell PTX-resistance, our data are consistent with other recent studies indicating that resistance to PTX is associated with up-regulation of autophagy in EOC cells. The administration of EMSO can augment the activity of PTX, but only at sub-lethal doses. EMSO combination of PTX has been shown to be feasible with a good toxicity profile. An increase in cell death was observed when PTX was combinated with sub-lethal doses of EMSO. We also showed that sublethal doses of EMSO exerts their cytotoxic action through a caspase-independent apoptotic-like cell death.

Despite our important findings, our study has several limitations. This analysis was limited to two selected EOC cells and one basic anticancer drug. We also did not perform an in vivo study to assess the potential clinical relevance of the in vitro results.

\section{Conclusions}

Clinical and experimental approaches were combined to demonstrate that V-ATPase D1 regulated YAP expression mediated PTX-resistance in EOC. To this end, drugs targeting the V-ATPase D1/YAP signaling pathway can be specifically developed to overcome the occurrence of tumor resistance in EOC. Thus, EMSO may be useful as a chemosensitizer in the treatment of patients with PTX-resistance EOC.

\section{Methods}

\section{Patients and tissue specimens}

Tumor samples from patients with ovarian cancer were acquired from the First Affiliated Hospital of An Hui Medical University (PJ2017-0704) and a written informed consent was approved by the First Affiliated Hospital of An Hui Medical University Institutional 


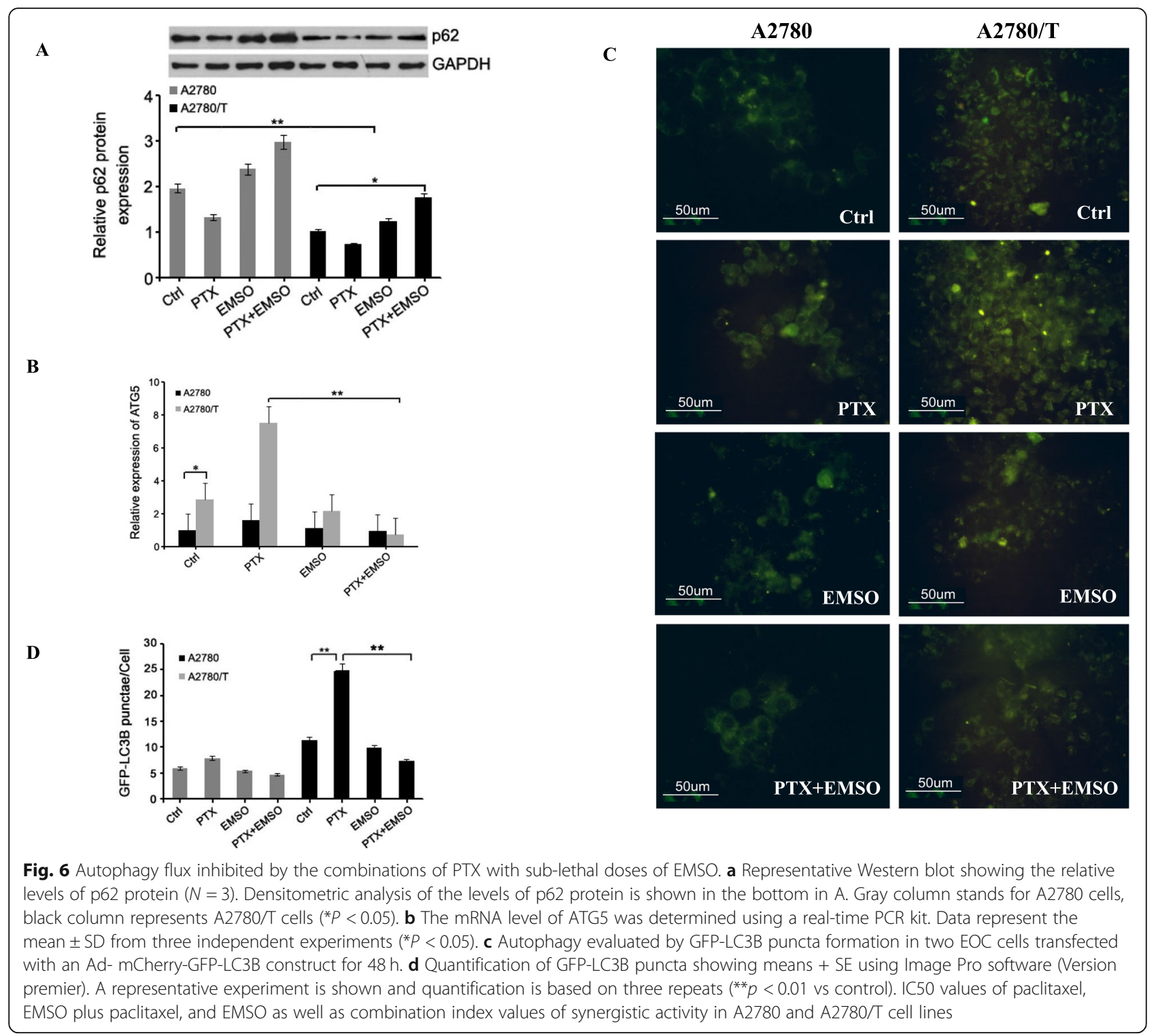

Review Board. Twelve normal ovarian specimens were obtained during surgery from women with myoma of uterus. A single gynecologic pathologist (I-G Do) examined the specimens using hematoxylin and eosin staining. Specimens were selected in analysis if they comprised more than $90 \%$ tumor cells. Data was collected from electronic and paper medical records.

\section{Reagents}

Esomeprazole sodium was purchased from AstraZeneca (Sweden) and dissolved to $10 \mathrm{mmol} / \mathrm{L}$ in saline before use. PTX injection was purchased from Aosaikang Co., Ltd. (Jiangsu, China). Z-VAD-FMK was purchased from Calbiochem (USA).

\section{Cell lines and culture}

Human EOC cell lines (A2780 and A2780/Taxol) were purchased from Hui Ying Biological Technology Co., Ltd., China. PTX-sensitive A2780 Cells was maintained in complete DMEM, high glucose (Hyclone, USA) supplemented with $10 \%$ fetal bovine serum. PTX-resistant A2780/Taxol (A2780/T) cells were cultured in RPMI 1640 supplemented with $10 \%$ fetal bovine-serum medium, first the A2780/T cells were exposed to $100 \mathrm{nM}$ PTX for $24 \mathrm{~h}$, then the medium was changed to fresh one without PTX. When cells reached almost $80 \%$ confluency, the cells were incubated with increasing concentrations of PTX to finally obtain the cells resistant to $1200 \mathrm{nM}$ PTX. For maintenance of PTXresistance phenotype, $250 \mathrm{nM}$ PTX was added into the normal medium. The drug resistant cells were cultured in 
PTX-free medium for at least 2 weeks prior to being used in experiments. All cells were cultured at $37{ }^{\circ} \mathrm{C}$ in a humidified atmosphere incubator with $5 \% \mathrm{CO} 2$.

\section{Immunohistochemical analysis}

Immunohistochemical studies were carried out on formalin-fixed, paraffin- embedded, $4 \mu \mathrm{m}$ thick tissue sections and stained with hemoxylin and eosin. After deparaffinization and antigens retrieval, slides were washes, blocked and incubated with V-ATPase D1(Santa Cruz, USA) and YAP (Santa Cruz, USA) at $4{ }^{\circ} \mathrm{C}$ overnight, followed by $1 \mathrm{~h}$ incubation with biotinylated goat-anti-mouse or biotinylated goat-anti-rabbit secondary antibody. Immunostaining was performed with diaminobenzidine (DAB) using the streptavidin-biotin complex/horseradish peroxidase (sABCHRP) method. Sections were counterstained with hematoxylin, and then mounted in medium. For each sample four microscopic fields $(\times 200)$ in three different sections were counted. The intensity of staining was graded on a semi quantitative scale from 0 to 3 , where $0=$ no staining, $1+=$ weak staining, $2+=$ moderate staining, and $3+=$ strong staining. The range of possible scores was between 0 and 250.

\section{Cell transfection}

To figure out if YAP directly regulated by V-ATPase expression, we generated stable V-ATPase D1 knockdown YAP-high/PTX-resistant A2780/T cells by transfection of V-ATPase D1 shRNA plasmid (Santa Cruz, USA). Stable clones were selected with G418 (Gibco, USA). To investigate the relationship between YAP and PTX resistance, YAP plasmids and siYAP-RNA were transfected, respectively, into YAP-low/PTX-sensitive A2780 cells or YAP-high/PTX-resistant A2780/T cells, using Lipofectamine 2000 transfection reagent (Invitrogen, USA) as per manufacturer's instructions. After incubation for $48 \mathrm{~h}$, the transfected cells were used for the following experiments.

\section{Luciferase assay}

Human YAP cDNA was inserted into the expression vector pCL3-based verctos, resulting in the Flag-tagged YAP (Flag-YAP). YAP wild type or S94A mutant, and TEAD1 shRNAs were designed in a region identical in TEAD1, then stably co-transfected with a Renila luciferase expression plasmid into cells. Luciferase activities were analyzed using a dual-luciferase reporter kit (Promega, USA). Transfections were performed in triplicate and repeated three times to ensure reproducibility.

\section{Measurement of intracellular $\mathrm{pH}$ levels}

BCECF-AM (Beyotime Biotechnology, China) is the most widely used fluorescent indicator for intracellular
$\mathrm{pH}$. The BCECF-AM was excited at $488 \mathrm{~nm}$ with emission collected at $535 \mathrm{~nm}$. Cells $\left(1 \times 10^{5}\right.$ cells $)$ were seeded in a 35-mm confocal dish in RPMI1640 and high glucose DMEM with $10 \%$ FBS. The next day, cells were exposed to EMSO in serum free RPMI 1640 and high glucose DMEM. After $48 \mathrm{~h}$, the cells were treated with $1 \mu \mathrm{mol} / \mathrm{L}$ BCECF-AM solution, incubated at $37^{\circ} \mathrm{C}$ for $40 \mathrm{~min}$ and analyzed by fluorescence microscopy.

\section{Immunofluorescence assay}

Cells were grown on round glass coverslips (Thermo Fisher Scientific, USA) in $35 \mathrm{~mm}$ cell culture dishes. Following a 7-9 min fixation with $4 \%$ pre-chilled paraformaldehyde, the coverslips were washed with PBS, permeabilized with $0.5 \%$ Triton X-100-PBS for 5-10 min, and blocked with $5 \%$ bovine serum albumin-PBS for 60 min. The YAP antibody was incubated with the cells overnight at $4{ }^{\circ} \mathrm{C}$. After incubation with the appropriate secondary fluorescent antibody Alexa green $488 \mathrm{~nm}$ (Molecular Probes, Life Technologies, USA), nuclei were stained with DAPI (Beyotime Biotechnology, China) and the cell were immediately observed under a fluorescence microscope. For the co-localization analysis of VATPase D1 with plasma membrane, cells were washed and fixed as described above, but not permeabilized. After the immunofluorescence stain for the V-ATPase D1, cells were also stained with a pan-cadherin (Abcam, UK) that bind of the cell membrane.

\section{Cytotoxicity of a single and combined drug in PTX sensitive and resistant EOC cells}

Cell cytotoxicity was analyzed with Cell Counting Kit-8 (CCK-8) assay kit (Beyotime Biotechnology, China). Briefly, cells were seeded into flat-bottomed 96-well plates at a density of 8000 per well and incubated overnight. After cellular adhesion, the A2780/T cells were exposed to various doses of PTX $(0.04,0.2,0.9,5$, $23 \mu \mathrm{M})$ and in the absence or presence of EMSO $(150 \mu \mathrm{M})$, the A2780 cells were exposed to various doses of PTX $(0.01,0.05,0.25,1.25,7.5 \mu \mathrm{M})$ in the absence or presence of EMSO $(130 \mu \mathrm{M})$ for $48 \mathrm{~h}$ followed by treatment with $10 \mu \mathrm{l}$ of CCK-8 solution for an additional $1 \mathrm{~h}$ at $37^{\circ} \mathrm{C}$, and the absorbance was measured at $450 \mathrm{~nm}$ using a microplate reader (Perkin Elmer, USA). At least three independent experiments were performed.

\section{Cell apoptosis detection}

Apoptosis was induced by PTX $(0.25$ and $2 \mu \mathrm{M})$ with or without EMSO (130 and $150 \mu \mathrm{M})$ co-treatment for $48 \mathrm{~h}$ each. Apoptosis detection was carried out with Annexin VFITC and Propidium Iodide (PI) double staining assay kit (KeyGen Biotech, China), following the manufacturer's instruction. Apoptotic cells were uncovered using flow 
cytometry (BD Bioscience, USA). Data acquisition and analysis were done with CellQuest V3.3 (BD Bioscience, USA).

\section{Morphological detection of apoptosis by Hoechst-33342 assay}

Cells were harvested and washed in ice-cold PBS and fixed with $3.7 \%$ paraformaldehyde in PBS for $10 \mathrm{~min}$ at room temperature. Fixed cells were permeabilized with saponin and stained with Hoechst-33342 solution (Beyotime Biotechnology, China) for $10 \mathrm{~min}$ at room temperature. Nuclear morphology of cells was examined by fluorescence microscopy. The percentage of apoptosis was calculated by counting the condensed and fragmented nuclei in cells. The experiment was repeated three times.

\section{Green fluorescent protein-LC3 translocation}

Ad-mCherry-GFP-LC3B (Beyotime Biotechnology, China) was used to detect autophagy. Cells were transfected with Ad-mCherry-GFP-LC3B using Lipofectamine 2000 in serum-free medium for $240 \mathrm{~min}$ after which the medium was changed to a complete medium. After $24 \mathrm{~h}$, the transfected cells were exposed to PTX $(0.25$ and $2 \mu \mathrm{M})$ in the absence or presence of EMSO (130 and $150 \mu \mathrm{M})$ for $48 \mathrm{~h}$. The distribution and the fluorescence of mCherry-GFPLC3B were visualized by fluorescence microscopy.

\section{Real-time reverse transcription PCR}

Total RNA was extracted with Trizol Reagent (Invitrogen, USA) and quantified by a spectrophotometer. cDNA synthesis was carried out using M-MLV reverse transcriptase (Invitrogen, USA). Quantitative PCR experiments were performed on the 7500 Real-time PCR system (Applied Biosystems, USA) by using the SYBR Green PCR reagents (Takara, Japan). The levels of mRNA were calculated using the equation $2-\Delta \Delta C T$ and normalized to human $18 \mathrm{~s}$ mRNA levels.

\section{Western blotting analysis}

The total protein was extracted using RIPA lysis buffer (Beyotime Biotechnology, China) supplemented with protease inhibitors cocktail (Roche, USA). The proteins were quantified using BCATM Protein Assay Kit (Pierce, Appleton, USA). The western blot was performed according to the standard protocol.

\section{Enzyme-linked immunosorbent assay}

For the analysis of active caspase- 3 and caspase- 8 expression, cells were lysed in PRO-PRE Protein Extraction Solution (Intron Biotechnology, Korea). The protein concentration was determined using a BCA protein kit (Thermo Scientific, USA). The concentrations of active caspase- 3 and caspase- 8 (Invitrogen, USA) were determined using an Enzyme-linked immunosorbent assay
(ELISA) kits used according to the manufacturer's instructions. All samples were measured in triplicate.

\section{Statistical analysis}

The correlation between YAP and V-ATPase D1 was evaluated using Spearman's rank correlation coefficient test. The results are expressed as the mean + standard error (SE) or standard deviation (SD) of the raw data. The Student's t test was used to determine the statistical significance of differences between the control and test groups. A $p$ value of $<0.05$ was considered statistically significant.

Combination index (CI) values were calculated using CalcuSyn Version 2.1 according to the Chou-Talalay method for drug combinations (Chou, 2010). CI is a parameter that gives information about the effectiveness of drug combinations. Combination effects are defined as very strong synergism $(\mathrm{CI}<0.1)$, strong synergism $(0.1<\mathrm{CI}<0.3)$, synergism $\quad(0.3<\mathrm{CI}<0.7), \quad$ moderate synergism $(0.70<\mathrm{CI}<0.85)$, slight synergism $(0.85<\mathrm{CI}<$ $0.90)$, nearly additive $(0.9<\mathrm{CI}<1.1)$, or antagonistic (CI $>1.1$ ) (Chou, 2006).

\section{Abbreviations}

ATG5: Autophagy-related proteins 5; CCK-8: Cell Counting Kit-8; Cl: Combination index; ELISA: Enzyme-linked immunosorbent assay; EMSO: Esomeprazole; IC50: Half maximal inhibitory concentration; Paclitaxel: PTX; PI: Propidium lodide; PPI: Proton pump inhibitors; SE: Standard error; ShRNA: Short hairpin RNA; Sh-scr: Scrambled short hairpin RNA

\section{Acknowledgements}

The authors gratefully acknowledge all the volunteers who generously providing tissue samples for this study.

\section{Authors' contributions}

$X L$ and YSJ designed the project; HJ, SXY, LZM, LZL performed the experiments; $C Y, P X H$ interpreted and analyzed the data; $X L$ drafted the manuscript. All the authors have approved the submitted version and have agreed to be personally accountable for the contributions and for ensuring that questions related to the accuracy or integrity of any part of the work are answered.

\section{Funding}

This work was partially supported by grants from the National Natural Science Foundation of China (grant number: 81603138), the Special Fund for Guiding Local Science and Technology Development awarded by the Central Government of Anhui Province (grant number: 2017070802d149). The funding bodies represents government's fulfillment of their duty in maximizing the benefits from public research output in China.

Availability of data and materials Not applicable.

\section{Ethics approval and consent to participate}

This study was approved by the Institutional Ethics Committee of The First Affiliated Hospital of An Hui Medical University and according to the Declaration of Helsinki. Informed consent was also obtained from each participants.

Consent for publication

Not applicable.

Competing interests

The authors declare that they have no competing interests. 


\section{Author details}

'Department of Obstetrics \& Gynecology, First Affiliated Hospital, An Hui Medical University, Hefei 230020, Anhui, People's Republic of China. ${ }^{2}$ Anhui Province Key Laboratory of Reproductive Health and Genetics, Hefei 230020, Anhui, People's Republic of China. ${ }^{3}$ Department of Obstetrics and Gynecoloy, An Qing Municipal Hospital, An Qing 246003, AnHui, People's Republic of China. ${ }^{4}$ Central Laboratory, The Central Hospital of Wuhan, Tongji Medical College, Huazhong University of Science and Technology, Wuhan 430014, Hubei, People's Republic of China. ${ }^{5}$ Department of Gynecology, Guangdong Women and Children Hospital, Guangzhou 510010, Guangdong, People's Republic of China.

Received: 15 May 2019 Accepted: 20 September 2019 Published online: 12 November 2019

\section{References}

1. Pan D. The hippo signaling pathway in development and cancer. Dev Cell. 2010;19(4):491-505.

2. Fujimoto D, Ueda $Y$, Hirono $Y$, Goi T, Yamaguchi A. PAR1 participates in the ability of multidrug resistance and tumorigenesis by controlling hippo-YAP pathway. Oncotarget. 2015;6(33):34788-99.

3. Jeong W, Kim SB, Sohn BH, Park YY, Park ES, Kim SC, Kim SS, Johnson RL, Birrer M, Bowtell DSL, Mills GB, Sood A, Lee JS. Activation of YAP1 is associated with poor prognosis and response to taxanes in ovarian cancer. Anticancer Res. 2014;34(2):811-7.

4. Xiao L, Shi XY, Zhang Y, Zhu Y, Zhu L, Tian W, Zhu BK, Wei ZL. YAP induces cisplatin resistance through activation of autophagy in human ovarian carcinoma cells. OncoTargets Ther. 2016;9:1105-14.

5. Ivery MT, Le T. Modeling the interaction of paclitaxel with beta-tubulin. Oncol Res. 2003;14(1):1-19.

6. Joo Y, Schumacher B, Landrieu I, Bartel M, Smet-Nocca C, Jang A, Choi HS, Jeon NL, Chang KA, Kim HS, Ottmann C, Suh YH. Involvement of 14-3-3 in tubulin instability and impaired axon development is mediated by Tau. FASEB J. 2015;29(10):4133-44

7. Jinawath $\mathrm{N}$, Vasoontara C, Yap KL, Thiaville MM, Nakayama K, Wang TL, Shih IM. NAC-1, a potential stem cell pluripotency factor, contributes to paclitaxel resistance in ovarian cancer through inactivating Gadd45 pathway. Oncogene. 2009;28(18):1941-8.

8. Nishi T, Forgac M. The vacuolar (H+)-ATPases-nature's most versatile proton pumps. Nat Rev Mol Cell Biol. 2002;3(2):94-103.

9. Spugnini EP, Citro G, Fais S. Proton pump inhibitors as anti vacuolar-ATPases drugs: a novel anticancer strategy. J Exp Clin Cancer Res. 2010;29:44.

10. Kulshrestha A, Katara GK, Ginter J, Pamarthy S, Ibrahim SA, Jaiswal MK, Sandulescu C, Periakaruppan R, Dolan J, Gilman-Sachs A, Beaman KD. Selective inhibition of tumor cell associated vacuolar-ATPase 'a2' isoform overcomes cisplatin resistance in ovarian cancer cells [J]. Mol Oncol. 2016; 10(6):789-805

11. Luciani F, Spada M, De Milito A, Molinari A, Rivoltini L, Montinaro A, Marra M, Lugini L, Logozzi M, Lozupone F, Federici C, lessi E, Parmiani G, Arancia G, Belardelli F, Fais S. Effect of proton pump inhibitor pretreatment on resistance of solid tumors to cytotoxic drugs. J Natl Cancer Inst. 2004;96(22):1702-13.

12. Hernandez A, Serrano-Bueno G, Perez-Castineira JR, Serrano A. Intracellular proton pumps as targets in chemotherapy: V-ATPases and cancer. Curr Pharm Des. 2012;18(10):1383-94.

13. Enzo E, Santinon G, Pocaterra A, Aragona M, Bresolin S, Forcato M, Grifoni D, Pession A, Zanconato F, Guzzo G, Bicciato S, Dupont S. Aerobic glycolysis tunes YAP/TAZ transcriptional activity. EMBO J. 2015;34(10):1349-70.

14. Moroishi T, Hansen CG, Guan KL. The emerging roles of YAP and TAZ in cancer. Nat Rev Cancer. 2015:15(2):73-9.

15. Moscat J, Diaz-Meco MT. p62 at the crossroads of autophagy, apoptosis, and cancer. Cell. 2009;137(6):1001-4.

16. Yousefi S, Perozzo R, Schmid I, Ziemiecki A, Schaffner T, Scapozza L, Brunner T, Simon HU. Calpain-mediated cleavage of Atg5 switches autophagy to apoptosis. Nat Cell Biol. 2006;8(10):1124-32

17. Lee YY, Jeon HK, Hong JE, Cho YJ, Ryu JY, Choi JJ, Lee SH, Yoon G, Kim WY, Do IG, Kim MK, Kim TJ, Choi CH, Lee JW, Bae DS, Kim BG. Proton pump inhibitors enhance the effects of cytotoxic agents in chemoresistant epithelial ovarian carcinoma. Oncotarget. 2015:6(33):35040-50.

18. Xia Y, Chang T, Wang Y, Liu Y, Li W, Li M, Fan HY. Correction: YAP Promotes Ovarian Cancer Cell Tumorigenesis and Is Indicative of a Poor Prognosis for Ovarian Cancer Patients. PLoS One. 2016;11(3):e0152712.
19. Ferrari S, Perut F, Fagioli F, Brach Del Prever A, Meazza C, Parafioriti A, Picci P. Gambarotti M, Avnet S, Baldini N, Fais S. Proton pump inhibitor chemosensitization in human osteosarcoma: from the bench to the patients' bed. J Transl Med. 2013;11:268.

20. Avnet S, Lemma S, Cortini M, Pellegrini P, Perut F, Zini N, Kusuzaki K, Chano T, Grisendi G, Dominici M, De Milito A, Baldini N. Altered pH gradient at the plasma membrane of osteosarcoma cells is a key mechanism of drug resistance. Oncotarget. 2016;7(39):63408-23.

21. Azzarito T, Venturi G, Cesolini A, Fais S. Lansoprazole induces sensitivity to suboptimal doses of paclitaxel in human melanoma. Cancer Lett. 2015;356(2 Pt B):697-703.

22. Marino ML, Fais S, Djavaheri-Mergny M, Villa A, Meschini S, Lozupone F, Venturi G, Della Mina P, Pattingre S, Rivoltini L, Codogno P, De Milito A. Proton pump inhibition induces autophagy as a survival mechanism following oxidative stress in human melanoma cells. Cell Death Dis. 2010;1:e87.

23. Yeo M, Kim DK, Kim YB, Oh TY, Lee JE, Cho SW, Kim HC, Hahm KB. Selective induction of apoptosis with proton pump inhibitor in gastric cancer cells. Clin Cancer Res. 2004;10(24):8687-96.

24. Chen M, Zou X, Luo H, Cao J, Zhang X, Zhang B, Liu W. Effects and mechanisms of proton pump inhibitors as a novel chemosensitizer on human gastric adenocarcinoma (SGC7901) cells. Cell Biol Int. 2009;33(9):1008-19.

25. Chen M, Huang SL, Zhang XQ, Zhang B, Zhu H, Yang WW, Zou XP. Reversal effects of pantoprazole on multidrug resistance in human gastric adenocarcinoma cells by down-regulating the V-ATPases/mTOR/HIF-1alpha/ P-gp and MRP1 signaling pathway in vitro and in vivo. J Cell Biochem. 2012; 113(7):2474-87.

26. Udelnow A, Kreyes A, Ellinger $S$, Landfester $K$, Walther $P$, Klapperstueck $T$, Wohlrab J, Henne-Bruns D, Knippschild U, Würl P. Omeprazole inhibits proliferation and modulates autophagy in pancreatic cancer cells. PLoS One. 2011:6(5):e20143.

27. Zhang S, Wang Y, Li SJ. Lansoprazole induces apoptosis of breast cancer cells through inhibition of intracellular proton extrusion. Biochem Biophys Res Commun. 2014:448(4):424-9.

28. Wang BY, Zhang J, Wang JL, Sun S, Wang ZH, Wang LP, Zhang QL, LV FF, Cao EY, Shao ZM, Fais S, Hu XC. Intermittent high dose proton pump inhibitor enhances the anti tumor effects of chemotherapy in metastatic breast cancer. J Exp Clin Cancer Res. 2015;34:85

29. Goh W, Sleptsova-Freidrich I, Petrovic N. Use of proton pump inhibitors as adjunct treatment for triple-negative breast cancers. An introductory study. J Pharm Pharm Sci. 2014;17(3):439-46.

30. Tavares-Valente D, Baltazar F, Moreira R, Queirós O. Cancer cell bioenergetics and $\mathrm{pH}$ regulation influence breast cancer cell resistance to paclitaxel and doxorubicin. J Bioenerg Biomembr. 2013;45(5):467-75.

31. Arzu YO, Haluk Barbaros O, Mehmet S, Buse C, Güven K, Şeniz K, Engin U. Combination of esomeprazole with chemotherapeutics results in more pronounced cytotoxic effect via apoptosis on A549 non small-cell lung cancer cell line. Turk J Biol. 2017:41:231-41.

32. Canitano A, lessi E, Spugnini EP, Federici C, Fais S. Proton pump inhibitors induce a caspase- independent antitumor effect against human multiple myeloma. Cancer Lett. 2016;376(2):278-83.

33. Tan Q, Joshua AM, Wang M, Bristow RG, Wouters BG, Allen CJ, Tannock IF. Up-regulation of autophagy is a mechanism of resistance to chemotherapy and can be inhibited by pantoprazole to increase drug sensitivity. Cancer Chemother Pharmacol. 2017;79(5):959-69.

34. Pagotto A, Pilotto G, Mazzoldi EL, Nicoletto MO, Frezzini S, Pastò A, Amadori A. Autophagy inhibition reduces chemoresistance and tumorigenic potential of human ovarian cancer stem cells. Cell Death Dis. 2017;8(7): e2943.

35. Rao SV, Solum G, Niederdorfer B, Nørsett KG, Bjørkøy G, Thommesen L. Gastrin activates autophagy and increases migration and survival of gastric adenocarcinoma cells. BMC Cancer. 2017;17(1):68.

36. Hu F, Zhao Y, Yu Y, Fang JM, Cui R, Liu ZQ, Guo XL, Xu Q. Docetaxelmediated autophagy promotes chemoresistance in castration-resistant prostate cancer cells by inhibiting STAT3. Cancer Lett. 2017:416:24-30.

37. Sannino S, Brodsky JL. Targeting protein quality control pathways in breast cancer. BMC Biol. 2017:15(1):109.

38. Amaravadi RK, Kimmelman AC, Debnath J. Targeting Autophagy in Cancer: Recent Advances and Future Directions. Cancer Discov. 2019:9(9):1167-81.

39. Liu F, Liu D, Yang Y, Zhao S. Effect of autophagy inhibition on chemotherapy- induced apoptosis in A549 lung cancer cells. Oncol Lett. 2013;5(4):1261-5. 
40. Janku F, McConkey DJ, Hong DS, Kurzrock R. Autophagy as a target for anticancer therapy. Nat Rev Clin Oncol. 2011;8(9):528-39.

41. Tan Q, Joshua AM, Saggar JK, Yu M, Wang M, Kanga N, Zhang JY, Chen X, Wouters BG, Tannock IF. Effect of pantoprazole to enhance activity of docetaxel against human tumour xenografts by inhibiting autophagy. Br J Cancer. 2015;112(5):832-40.

\section{Publisher's Note}

Springer Nature remains neutral with regard to jurisdictional claims in published maps and institutional affiliations.

Ready to submit your research? Choose BMC and benefit from:

- fast, convenient online submission

- thorough peer review by experienced researchers in your field

- rapid publication on acceptance

- support for research data, including large and complex data types

- gold Open Access which fosters wider collaboration and increased citations

- maximum visibility for your research: over $100 \mathrm{M}$ website views per year

At $\mathrm{BMC}$, research is always in progress.

Learn more biomedcentral.com/submissions 